\title{
Migraine and Fish Oil
}

\author{
Simin Mouodi' (1), Marjan Mouodi² (D), Shervin Rezaei Majd³ (D), Amirmohamad Rezaei Majd 4 (D) \\ 'Social Determinants of Health Research Center, Babol University of Medical Sciences Health Research Institute, Babol, Iran \\ 2Department of Endocrinology and Metabolism, Tehran University of Medical Sciences School of Medicine, Tehran, Iran \\ ${ }^{3}$ Department of Research and Development, Scott Protein Products Company, Babol, Iran \\ ${ }^{4}$ Department of General Practice, Babol University of Medical Sciences School of Medicine, Babol, Iran
}

ORCID IDs of the authors: S.M. 0000-000I-7868-9360; M.M. 0000-0002-5I38-4855; S.R.M. 0000-000I-6900-5I07; A.R.M. 0000-00021984-8795.

Cite this article as: Mouodi S, Mouodi M, Majd SR, Majd AR. Migraine and Fish Oil. Cyprus J Med Sci 2019; 4(3): 257-6I.

Considering the importance of migraine as the seventh cause of disability globally, this study was conducted to evaluate the effectiveness of fish oil and omega-3 polyunsaturated fatty acids (PUFA) on migraine. In this review article, we included all clinical trials and review articles from four databases (Pubmed, the Cochrane database of systematic reviews, Scopus, and Clinicalkey), published from January I, 1990, to August 7, 2018, in which the treatment effects of fish oil or PUFA for the prevention or control of migraine attacks, either in basic science or clinical field, have been studied. At first, 54 articles or book chapters were found, and after reviewing their study design, 13 clinical trials and review articles were included in the study. Most of reviewed articles, including five clinical trials and four review articles, represented the positive impact of fish oil and omega-3 PUFA for improvement in frequency, intensity, or duration of migraine headache; however, a definite daily dosage and duration of treatment have not been defined. Although the evidence that supports the positive impact of fish oil and PUFA in the prevention and control of migraine is frequent, more evidence and longitudinal study designs are required to confirm the positive impact of fish oil on migraine. Furthermore, research is needed to define an appropriate daily dosage and treatment duration of fish oil and PUFA in migraine patients.

Keywords: Fish oil, migraine, omega-3 fatty acids

\section{INTRODUCTION}

Migraine manifests by recurrent, episodic headache attacks, which may or may not be preceded by a focal neurologic symptom (aura) (I-3). It is a debilitating disorder, affecting $2.6 \%-21.7 \%$ of general population, worldwide (4). Its lifetime prevalence has been reported to range between $13 \%$ and $33 \%$ (5). Self-reported prevalence rates of migraine and severe headache among US adult population were reported as $15.3 \%$ ( $9.7 \%$ for men and $20.7 \%$ for women) (6). Ninety percent of all headaches are either migraine, tension-type headache, or a mixture of them (7). The Global Burden of Disease Study 2015 represented migraine as the seventh cause of disability globally (8). A higher prevalence of this disorder has been reported in adults aged 18-44 years, the unemployed, people with lower family income, and the elderly and disabled individuals (6).

The mechanisms and contributing factors of a migraine attack are described in Figure I (2).

Migraine treatment includes both preventive therapy, for reducing the frequency and severity of migraine attacks, and acute therapy, for aborting acute symptoms. Treatment can be divided into pharmacological and psychological intervention approaches $(9,10)$, or specific and non-specific medications (II).

Fish and fish oils are rich in omega-3 polyunsaturated fatty acids (PUFA). They have several cellular and physiologic mechanisms of action, which produce the anti-inflammatory effects of this compound (I2).

Some previous studies demonstrated that the fish oil and PUFA intake could be effective in the prevention or control of migraine due to their anti-inflammatory properties, vascular relaxation effects, and inhibition of serotonin release from platelets (7); and some other did not confirm a positive impact of fish oil on migraine. The aim of this research was to review published scientific manuscripts in which the effectiveness of fish oil in the prevention or acute treatment of migraine attacks has been assessed. 
We searched clinical trials and reviewed articles in four databases (Pubmed, the Cochrane database of systematic reviews, Scopus and Clinicalkey) from January I, 1990, to August 7, 2018. At first, all of clinical trials, systematic reviews, and review articles that used the entry terms ("Disorder, Migraine" OR "Disorders, Migraine" OR "Migraine Disorder" OR "Migraine" OR "Migraines" OR "Migraine Headache" OR"Headache, Migraine" OR "Headaches, Migraine" OR "Migraine Headaches" OR "Acute Confusional Migraine" OR "Acute Confusional Migraines" OR "Migraine, Acute Confusional" OR "Migraines, Acute Confusional" OR "Status Migrainosus" OR "Hemicrania Migraine" OR "Hemicrania Migraines" OR "Migraine, Hemicrania" OR "Migraines, Hemicrania" OR "Migraine Variant" OR "Migraine Variants" OR "Variant, Migraine" OR "Variants, Migraine" OR "Sick Headache" OR "Headache, Sick" OR "Headaches, Sick" OR "Sick Headaches" OR "Cervical Migraine Syndrome" OR "Cervical Migraine Syndromes" OR "Migraine Syndrome, Cervical" OR "Migraine Syndromes, Cervical") AND ("fish oil" OR "Omega 3 Fatty Acids") in title, abstract, or keywords were included. We also reviewed reference lists of included studies to identify the

Factors

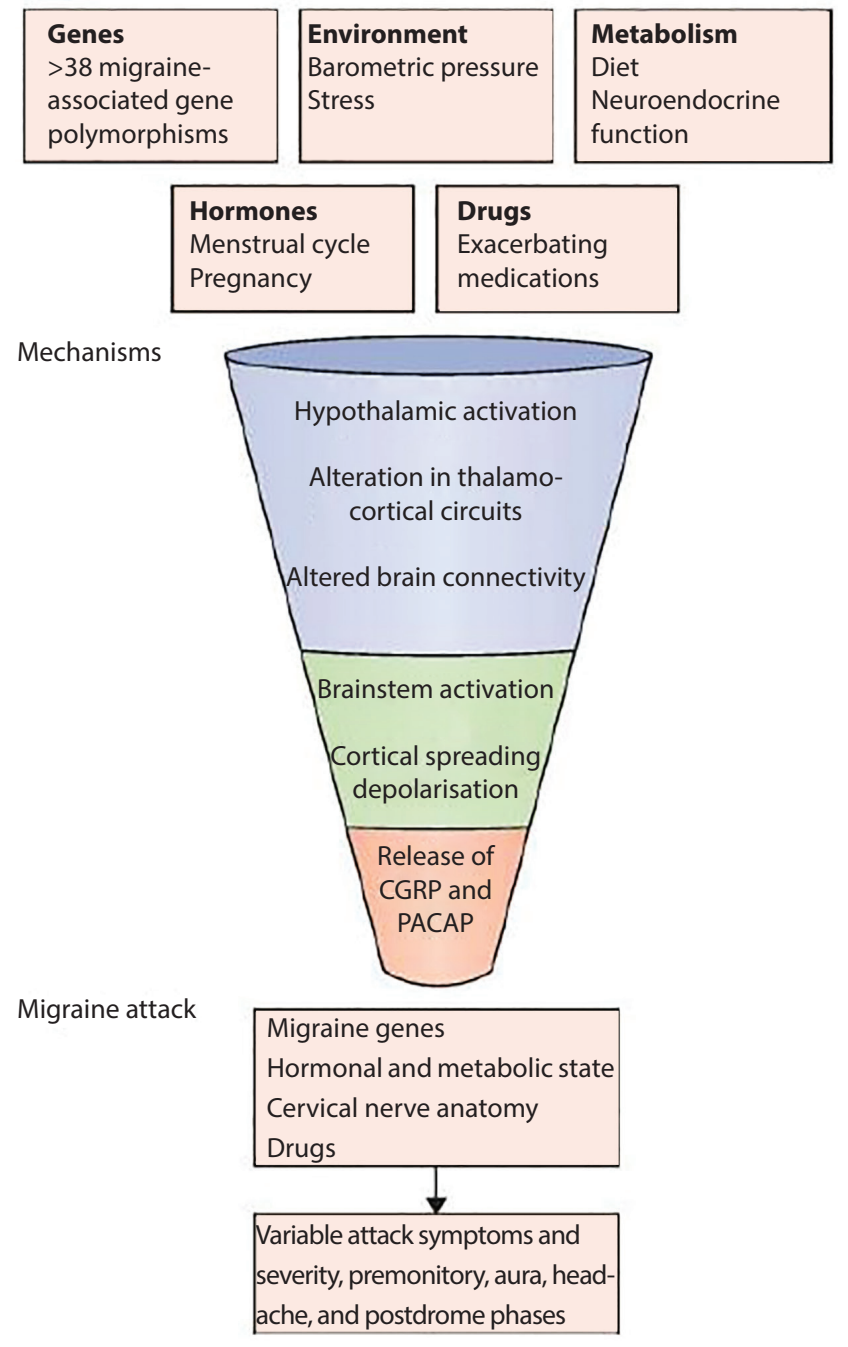

FIGURE I. Mechanisms and contributing factors of a migraine attack (Adapted from: Charles A. The pathophysiology of migraine: implications for clinical management. Lancet Neurol. 2018;17:174-82Figure courtesy of Andrew Charles - used with permission) articles related to search criteria. We searched published manuscripts in all languages. Two reviewers updated searches of the abstracts.

We included clinical trials and review articles that studied the treatment effects of fish oil or PUFA in the prevention or control of migraine attacks, either in basic science or clinical field. Relevant articles were selected using a two-phase process. Two researchers reviewed all identified abstracts for eligibility. Second, full text articles were revised to determine the mentioned treatment effects of fish oil or PUFA, including the prevention or improvement in frequency, duration, and intensity or characteristics of migraine headache. All the interventional studies and review articles regardless of the duration and the size of study population were included. The evidence published before 1990 was excluded.

Two authors, not blinded to data sources, summarized the included studies. Overall quality assessment was performed emphasizing the treatment effects of fish oil or PUFA on the prevention of migraine attack or control of its symptoms.

\section{CONCLUSION}

We found 54 articles or book chapters in the four mentioned databases in which the association between fish oil and migraine has been studied. After reviewing the study design of these manuscripts, there were 13 clinical trials and review articles included in the study. The included studies are summarized in Table I. This table shows that six clinical trials and five review articles studied the treatment effect of fish oil or omega-3 PUFA on clinical aspects of migraine, such as its frequency, severity, or duration; two clinical trials studied the treatment effect of PUFA on immunologic aspects of migraine. Seven of the included studies were published from 2016 to 2018.

Most of reviewed articles including five clinical trials (13-16) and four review articles (14, 17-19) represented the positive impact of fish oil and PUFA on the improvement in frequency, intensity, or duration of migraine headache; however, a definite daily dosage and duration of treatment have not been defined.

There were three clinical trials (20-22) that reported no significant statistical difference between the case and control groups regarding the treatment effects of fish oil in the prevention or control of migraine. In addition, Rajapakse in his review article reported non-adequate evidence to confirm the prophylactic effect of PUFA for migraine (23), and Maghsoumi-Norouzabad showed that omega-3 PUFA did not have a positive effect in the frequency and intensity of migraine headache, although it was effective in the reduction of migraine duration (14).

Soares evaluated 60 patients with chronic migraine undergoing prophylactic treatment with amitriptyline. The patients who received omega-3 PUFA for 2 months were compared to the control group receiving placebo, and they experienced a reduction in the number of days of headache. Furthermore, it was suggested that omega-3 PUFA could be useful in the prevention of migraine headache (I3). Ramsden (I5) and Tajmirriahi (16) reported a similar positive effect of fish oil or PUFA in the prevention of headache attacks in their clinical trials conducted among the adult study population. Ramsden applied a combination of 


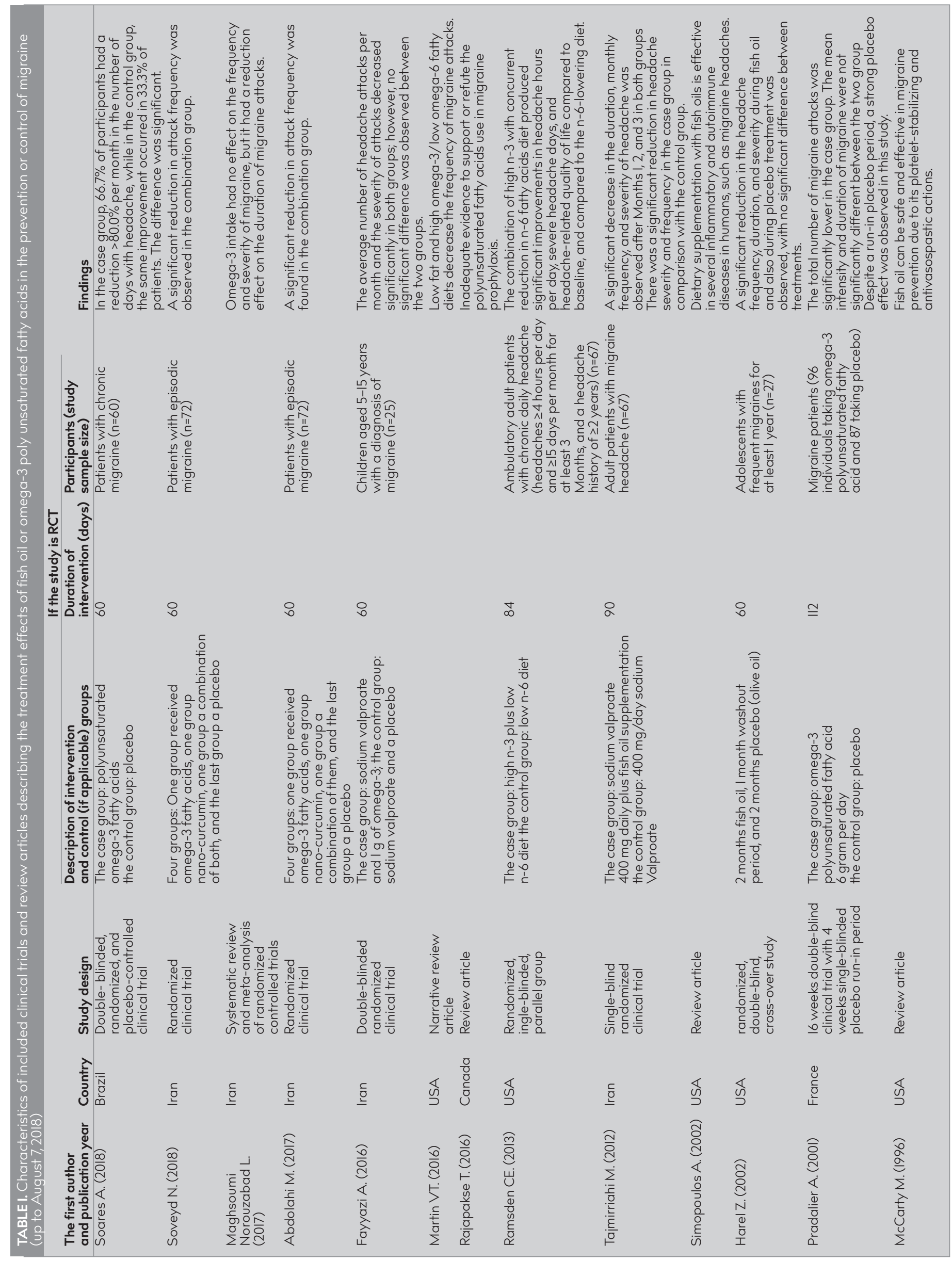


omega-3 PUFA intervention besides the reduction of omega-6 fatty acids in a daily food program (15). Tajmirriahi compared the treatment effect of fish oil administration (180 milligram/ day) plus sodium valproate $400 \mathrm{mg} /$ day for 3 months in migraine patients with those who received only sodium valproate. In this research, a significant reduction in headache frequency was observed only during the lst month of treatment; and this reduction was not significant during the 2 nd and $3 \mathrm{rd}$ month of treatment (16). Soveyd (24) and Abdolahi (25) evaluated the effect of omega-3 PUFA on immunologic aspects of migraine in their clinical trials, and headache frequency was the secondary outcome that they examined. They observed a significant reduction in migraine attacks in patients who received a combination of omega-3 PUFA and nano-curcumin.

Fayyazi examined the treatment effect of omega-3 PUFA in pediatric migraine. He observed that children aged 5-15 years treated with a combination of omega-3 PUFA (I gram per day) and sodium valproate for 2 months had a reduction in headache frequency and severity; however, the difference was not statistically significant between the case and control groups (22).

Although multiple factors and mechanisms have been described in the pathophysiology of migraine attacks (2), the origin of headache is not completely understood; recent evidence shows the effect of some vasomodulators, released by peripheral nerve endings on blood vessels in the scalp and meninges; furthermore, an inflammation and edema in blood vessels, with an increased sensitivity to mechanical stimulation are thought to be related to headache initiation. In addition, some receptors, such as nitric oxide, glutamate, and vanilloid, are also supposed to be involved in migraine (7). Some other evidence suggested that structural brain changes were more common in migraine patients, especially the patients with aura, than in control groups (26).

The exact mechanism of action of fish oil and omega-3 PUFAs in the prevention and control of migraine is still unclear, but it seems that their effect to inhibit multiple aspects of inflammation $(27,28)$; their effects on neuropeptides, neuro-receptors, and ion channels $(29,30)$; sympathetic nervous system (31); and also their vasomodulation impact (32) can justify their positive effect to improve migraine headache.

The most important limitation of this study was a non-specific quality assessment of included studies. It is suggested to future researchers to evaluate the treatment effect of fish oil and omega-3 PUFA with a different dosage and duration on the frequency, severity, and duration of migraine attacks.

Although the evidence supporting the positive impact of fish oil and PUFA in the prevention and control of migraine is more frequent, more evidence and longitudinal study designs need to confirm the positive impact of fish oil on migraine. Furthermore, research is needed to define an appropriate daily dosage and treatment duration of fish oil and PUFA in migraine patients.

Peer-review: Externally peer-reviewed.

Author contributions: Concept - S.M., M.M., S.R.M.; Design - S.M., M.M., S.R.M.; Supervision - S.M., M.M., S.R.M.; Resource - S.M., M.M., S.R.M.;
Materials - S.M., M.M., S.R.M., A.R.M.; Data Collection and/or Processing - S.M., M.M., S.R.M., A.R.M.; Analysis and/or Interpretation - S.M., M.M., S.R.M.; Literature Search - S.M., M.M., S.R.M., A.R.M.; Writing - S.M., M.M., S.R.M.; Critical Reviews - S.M., M.M., S.R.M.

Acknowledgements: Hereby, the support of the Vice-Chancellor for Research and Technology of Babol University of Medical Sciences for providing access to the mentioned data sources is appreciated.

Conflict of Interest: The authors have no conflicts of interest to declare.

Financial Disclosure: The authors declared that this study has received no financial support.

\section{REFERENCES}

I. Loder E, Rizzoli P. Pharmacologic prevention of migraine: a narrative review of the state of the art in 2018. Headache 2018; 58(Suppl 3): 218-29. [CrossRef]

2. Charles A. The pathophysiology of migraine: implications for clinical management. Lancet Neurol 2018; 17: 174-82. [CrossRef]

3. Burstein R, Noseda R, Borsook D. Migraine: multiple processes, complex pathophysiology. J Neurosci 2015; 35(17): 6619-29. [CrossRef]

4. Yeh WZ, Blizzard L, Taylor BV. What is the actual prevalence of migraine?. Brain Behav 2018; 8(6): e00950. [CrossRef]

5. Dodick DW. Migraine. Lancet 20|8; 39|: |3|5-30. [CrossRef]

6. Burch R, Rizzoli P, Loder E. The prevalence and impact of migraine and severe headache in the united states: figures and trends from government health studies. Headache 2018; 58(4): 496-505. [CrossRef]

7. Coeytaux RR, Mann JD. Headache. 2018; Chapter 12: 108. Available from: www. clinicalkey.com. [CrossRef]

8. GBD 2015 Disease and Injury Incidence and Prevalence Collaborators. Global, regional, and national incidence, prevalence, and years lived with disability for 310 diseases and injuries, 1990-2015: a systematic analysis for the Global Burden of Disease Study 2015. Lancet 2016; 388(I0053): 1545-602. [CrossRef]

9. Sullivan A, Cousins S, Ridsdale L. Psychological interventions for migraine: a systematic review. J Neurol 2016; 263(I2): 2369-77. [CrossRef]

10. Bulaj G. Combining non-pharmacological treatments with pharmacotherapies for neurological disorders: a unique interface of the brain, drug-device, and intellectual property. Front Neurol 2014; 5: 126. [CrossRef]

II. Antonaci F, Ghiotto N, Wu S, Pucci E, Costa A. Recent advances in migraine therapy. Springerplus 2016; 5: 637. [CrossRef]

12. Pizzorno JE, Paul C, Schauss AG. Fish Oils (Omega-3 Fatty Acids, Docosahexaenoic Acid, Eicosapentaenoic Acid, Dietary Fish, and Fish Oils) in Textbook of Natural Medicine. 4th ed. St. Louis, MO: Elsevier Churchill Livingstone; 2013: chap 91. [CrossRef]

13. Soares AA, Louçana PMC, Nasi EP, Sousa KMH, Sá OMS3, Silva-Néto RP. A double- blind, randomized, and placebo-controlled clinical trial with omega-3 polyunsaturated fatty acids (OPFA -3) for the prevention of migraine in chronic migraine patients using amitriptyline. Nutr Neurosci 2018; 2I(3): 219-23. [CrossRef]

14. Maghsoumi-Norouzabad L, Mansoori A, Abed R, Shishehbor F. Effects of omega-3 fatty acids on the frequency, severity, and duration of migraine attacks: A systematic review and meta-analysis of randomized controlled trials. Nutr Neurosci 2017; 30: I-I0. [CrossRef]

15. Ramsden CE, Faurot KR, Zamora D, Suchindran CM, Macintosh BA, Gaylord S, et al. Targeted alteration of dietary n-3 and n-6 fatty acids for the treatment of chronic headaches: A randomized trial. Pain 2013; 154(II): 10. [CrossRef]

16. Tajmirriahi M, Sohelipour M, Basiri K, Shaygannejad V, Ghorbani A, Saadatnia M. The effects of sodium valproate with fish oil supplementation or alone in migraine prevention: A randomized single-blind clinical trial. Iran J Neurol 20I2; II(I): 2I-4.

17. Martin VT, Vij B. Diet and Headache: Part 2. Headache 2016; 56(9): 1553-62. [CrossRef] 
18. Simopoulos A. Omega-3 fatty acids in inflammation and autoimmune diseases. J Am Coll Nutr 2002; 21(6): 495-505. [CrossRef]

19. McCarty M. Magnesium taurate and fish oil for prevention of migraine. Med Hypotheses 1996; 47: 461-6. [CrossRef]

20. Harel Z, Gascon G, Riggs S, Vaz R, Brown W, Exil G. Supplementation with omega-3 polyunsaturated fatty acids in the management of recurrent migraines in adolescents. J Adolesc Health 2002; 31(2): |54-61. [CrossRef]

21. Pradalier A, Bakouche P, Baudesson G, Delage A, Cornaille-Lafage $G$, Launay $J M$, et al. Failure of omega-3 polyunsaturated fatty acids in prevention of migraine: a double-blind study versus placebo. Cephalalgia 200I; 2I(8): 8I8-22. [CrossRef]

22. Fayyazi A, Khajeh A, Ghazavi A, Sangestani M. Omega 3 in childhood migraines: a double blind randomized clinical trial. Iran J Child Neurol 2016; IO(I): 9-13.

23. Rajapakse T, Pringsheim T. Nutraceuticals in migraine: a summary of existing guidelines for use. Headache 2016; 56(4): 808-16. [CrossRef]

24. Soveyd N, Abdolahi MI, Dialali M, Hatami M, Tafakhori A, Sarraf $P$, et al. The combined effects of omega -3 fatty acids and nano-curcumin supplementation on intercellular adhesion molecule-I (ICAM-I) gene expression and serum levels in migraine patients. CNS Neurol Disord Drug Targets 2018; 16(10): II20-6. [CrossRef]

25. Abdolahi M, Tafakhori A, Togha M, Okhovat AA, Siassi F, Eshraghian MR, et al. The synergistic effects of omega-3 fatty acids and nano-curcumin supplementation on tumor necrosis factor (TNF)-alpha gene expression and serum level in migraine patients. Immunogenetics 2017; 69(6): 37I-8. [CrossRef]

26. Bashir A, Lipton RB, Ashina S, Ashina M. Migraine and structural changes in the brain: a systematic review and meta-analysis. Neurology 2013; 8I(|4): 1260-8. [CrossRef]

27. Calder P. Omega-3 fatty acids and inflammatory processes: from molecules to man. Biochem Soc Trans 2017; 45(5): II05-I5. [CrossRef]

28. Laye S, Nadjar A, Joffre C, Bazinet RP. Anti-inflammatory effects of omega-3 fatty acids in the brain: physiological mechanisms and relevance to pharmacology. Pharmacol Rev 20l8; 70(I): 12-38. [CrossRef]

29. Zhang W, Wang $H$, Zhang $H$, Leak RK, Shi $Y$, Hu X, et al. Dietary supplementation with omega-3 polyunsaturated fatty acids robustly promotes neurovascular restorative dynamics and improves neurological functions after stroke. Exp Neurol 2015; 272: 170-80. [CrossRef]

30. Elinder F, Liin SI. Actions and mechanisms of polyunsaturated fatty acids on voltage-gated ion channels. Front Neurol 2017; 8: 43. [CrossRef]

31. La Rovere MT, Christensen JH. The autonomic nervous system and cardiovascular disease: role of n-3 PUFAs. Vascul Pharmacol 2015; 71: I-I0. [CrossRef]

32. Limbu R, Cottrell GS, McNeish AJ. Characterisation of the vasodilation effects of DHA and EPA, n-3 PUFAs (fish oils), in rat aorta and mesenteric resistance arteries. PloS one 2018; I3(2): e0192484. [CrossRef] 